\title{
Knowledge regarding basic concepts of hereditary cancers, and the available genetic counselling and testing services: A survey of general practitioners in Johannesburg, South Africa
}

\author{
C van Wyk, ${ }^{1,2}$ MSc (Med) Genetic Counselling; T-M Wessels, ${ }^{1,3}$ MSc (Med) Genetic Counselling, PhD; \\ J G R Kromberg, ${ }^{1}$ BA (Social Work), MA, PhD; A Krause, ${ }^{1} \mathrm{MB}$ BCh, $\mathrm{PhD}$

\begin{abstract}
${ }^{1}$ Division of Human Genetics, National Health Laboratory Service and School of Pathology, Faculty of Health Sciences, University of the Witwatersrand, Johannesburg, South Africa

${ }^{2}$ Current affiliation: Division of Health Sciences Education, Office of the Dean, Faculty of Health Sciences, University of the Free State, Bloemfontein, South Africa
\end{abstract} \\ ${ }^{3}$ Division of Human Genetics, Department of Pathology, Faculty of Health Sciences, University of Cape Town, South Africa
}

Corresponding author: Cvan Wyk(vanwykc2@ufs.ac.za)

\begin{abstract}
Background. In families with hereditary cancer, at-risk individuals can benefit from genetic counselling and testing. General practitioners (GPs) are ideally placed to identify such families and refer them appropriately.

Objective. To assess the practices, knowledge and attitudes of GPs regarding common hereditary cancers.

Methods. An exploratory research design was used. An existing questionnaire was adapted, piloted and mailed to 196 GPs in Johannesburg, South Africa. The 61 GPs (31.1\%) who completed and returned the questionnaire constituted the final sample. Data were analysed using descriptive statistics.

Results. The GPs obtained some information on cancer family history from their patients, but not enough to assess the risks. Altogether $22(36.1 \%)$ of the GPs referred patients to appropriate facilities for assessment and testing, while 32 (52.5\%) were aware of genetic testing services. Most (38/61, 62.3\%) were not familiar with the genetic counselling facilities available, but they felt patients should have counselling before testing. Less than half knew about possible paternal inheritance, or the low rate of hereditary mutations and their penetrance. Overall, the majority of GPs $(53 / 61,86.9 \%)$ were interested in learning more about cancer genetics and available services, and they expected to play an increasing role in the field in the future.

Conclusions. Many of the GPs in this study had limited knowledge about inherited cancers, cancer risk management and genetic services. Appropriate education needs to be increased so that they are better equipped to identify and refer families at risk.
\end{abstract}

S Afr Med J 2016;106(3):268-271. DOI:10.7196/SAMJ.2016.v106i3.10162

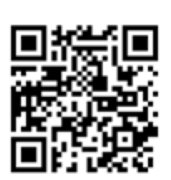

In the past decade the genetic contributions to cancer syndromes have become clearer ${ }^{[1]}$ and about 500 familial cancer syndromes have been described (a comprehensive list can be found at http://www. familialcancerdatabase.nl/). ${ }^{[2]}$ Recognition of cancer susceptibility in a family can enable individuals at risk to seek cancer genetic counselling. The aims of such counselling are to: (i) assess family histories in detail; (ii) estimate the risk of developing the familial cancer; (iii) provide information so that informed decisions about testing, surveillance and prophylactic surgery can be made; and (iv) offer support in partnership with attending healthcare professionals. ${ }^{[1]}$ This service is available in South Africa (SA) to persons who have a family history of cancer and their at-risk family members. The Division of Human Genetics, National Health Laboratory Service (NHLS), School of Pathology, Faculty of Health Sciences, University of the Witwatersrand (Wits), Johannesburg, and several other departments of human genetics throughout SA offer cancer genetics services.

The first steps in determining whether a hereditary cancer syndrome is present in a family are to gather detailed family, medical, and lifestyle histories and to obtain details of cancer sites and histological features of the tumours. ${ }^{[1]}$ Primary healthcare providers, in particular general practitioners (GPs), often have first-level contact with patients and are therefore ideally placed to identify individuals
Table 1. Medical and family history clues that can indicate whether an individual or family is at increased risk for a hereditary cancer (after Lalloo et al..$^{[1]}$ )

Two or more first- and/or second-degree relatives with the same cancer Several first-and/or second-degree relatives who have related types of cancer Two members in the family with the same rare cancer Two members in the family with related rare cancers Early age of onset for the specific cancer type (e.g. <50 years for breast cancer) Bilateral cancer

Multifocal tumours

More than one type of associated cancer in one individual Specific cancers in high-risk population groups (e.g. Afrikaner or Ashkenazi Jewish)

and families who may be at risk for an inherited cancer syndrome, and refer them appropriately to cancer genetic services. ${ }^{[3]}$ Guidelines for identifying individuals and/or families at risk for an inherited cancer are available, and they are summarised in Table 1.

Studies in the $\mathrm{USA}^{[4]}$ and Europe ${ }^{[5]}$ have explored the knowledge of primary healthcare physicians, including GPs, regarding cancer genetics. The findings showed that they had limited knowledge of 
cancer genetic conditions and services, but other studies showed that physicians accepted that they had an increasing role to play in referring to such services. ${ }^{[6,7]}$ Since more genetic tests for hereditary cancers are becoming available, and public awareness is increasing, the demand for cancer genetic services could also increase substantially. ${ }^{[6]}$ GPs as well as other healthcare professionals therefore need to understand the general principles of cancer genetics ${ }^{[4]}$ so that they are able to identify individuals and families at risk and refer them for cancer genetic counselling.

\section{Objective}

To investigate, among GPs in Johannesburg, their current knowledge regarding three common hereditary cancers (hereditary breast and ovarian cancer (HBOC), Lynch syndrome/hereditary non-polyposis colorectal cancer (HNPCC) and familial adenomatous polyposis (FAP)), their management of patients who could be at risk, and their attitudes towards learning more about inherited cancers and the relevant services.

\section{Methods}

A quantitative, exploratory research design was selected, as it was most suitable for the study. The research sample was obtained from a list of GPs held by the Department of Family Medicine, School of Clinical Medicine, Faculty of Health Sciences, University of the Witwatersrand. These GPs were all in private practice and were involved in part-time teaching of postgraduate medical students pursuing higher degrees or diplomas. Altogether 196 GPs were approached (all those listed).

The research tool was a modified structured self-administered questionnaire. The original questionnaire was designed by Wideroff et al. ${ }^{[4]}$ in the USA and used in this study with Dr Wideroff's permission. SA has a unique combination of ethnic groups, and a few changes were made to the questionnaire to make it suitable for the local situation.

The questionnaire was tested in a pilot study on five subjects (private GPs in a multipractice setting in Johannesburg) and minor amendments were made. A research recruitment package was then compiled and posted to the 196 listed GPs. The package contained an information sheet describing the study, the questionnaire, a consent sheet, and separate self-addressed envelopes (one for the completed questionnaire and the other for the response sheet, in order to ensure the anonymity of the GPs) and a covering letter.

The GPs were given 4 weeks to complete and return both the questionnaire and the consent sheet, after which a followup recruitment package was sent to non-responders. Seventy questionnaires were returned, including 61 completed questionnaires (round $1=26$, round $2=35$ ), one blank, and eight returned by the post office owing to incorrect addresses or for other unknown reasons. Data were collected between March and August 2005.

The responses from the completed questionnaires were entered into an Excel database and analysed using descriptive statistics and $t$-tests. Ethical approval for the study was provided by the Human Research Ethics Committee (Medical), Faculty of Health Sciences, University of the Witwatersrand (reference number M070219, 7 March 2005).

\section{Results}

\section{The sample}

A total of 61/196 GPs completed and returned the questionnaire, giving a final response rate of $31.1 \%$. A review of published research with a focus on mail survey research concluded that response rates can vary from $2.5 \%$ to $97.7 \%$, depending on the study. ${ }^{[8]}$ According
Table 2. Demographic characteristics of the respondents $(N=61)$

\begin{tabular}{ll}
\hline & $\boldsymbol{n}(\%)$ \\
\hline Age (years) & $14(23.0)$ \\
$30-39$ & $22(36.1)$ \\
$40-49$ & $11(18.0)$ \\
$50-59$ & $14(23.0)$ \\
$60-69$ & $61(100.0)$ \\
Primary qualification Bachelor of Medicine and Surgery \\
In addition to Bachelor of Medicine and Surgery \\
$\quad$ Degrees: BSc, BSc Hons, BPharm \\
Diplomas: DA, DCH \\
Average number of patients seen per week \\
Average hours per week spent in practice & $21(34.4)$ \\
\end{tabular}

to Neuman, ${ }^{[9]}$ a response rate of $31 \%$ is considered reasonable for a postal survey. The sample of GPs was affiliated with the University of the Witwatersrand and may have been relatively more inclined/ willing to participate in the research project. The demographic details of the respondents are given in Table 2. The GPs estimated that they saw an average of 110 patients (more females $(60 / 110,54.5 \%)$ than males $(50 / 110,45.5 \%)$ ) a week, and they worked on average 45 hours per week (range 7 - 72 hours). Forty-five $(45 / 67,67.2 \%)$ of the GPs had a limited family history of cancer themselves. About half of them $(32 / 61,52.5 \%)$ reported that they worked in a multiple practice setting with between 2 and 10 partners.

\section{Family history information, risk assessment management and referral}

The GPs stated that they gathered some medical and cancer history on new patients (Fig. 1). Significantly more GPs collected information on their patients (100.0\%) and on the patients' first-degree relatives $(93.4 \%)$ than on their second-degree relatives $(73.8 \%$; $p<0.001)$ or ages at cancer diagnosis $(72.1 \% ; p<0.001)$. However, the GPs were found to make use of several cancer screening procedures including mammography (98.4\%), clinical breast examination (95.1\%), prostate-specific antigen measurement $(91.8 \%)$, Pap smears (86.9\%), faecal occult blood tests (67\%), abdominal ultrasound (60.7\%) and CA-125 marker tests (57.4\%).

About half $(34 / 61,55.7 \%)$ of the respondents stated that some of their patients enquired about the possibility of an increased cancer risk. Overall, 24.6\% (15/61) reported that they assessed their patients' risk of having a hereditary cancer; however, they were not asked to describe how they assessed these risks. The

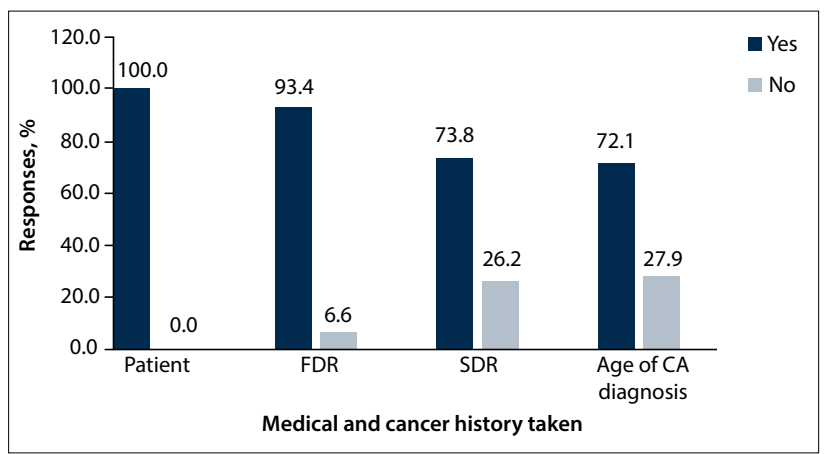

Fig. 1. Information collected from patients regarding cancer in the family. $(F D R=$ first-degree relatives; $S D R=$ second-degree relatives; $C A=$ cancer $)$ 
remainder $(75.4 \%, 46 / 61)$ were unsure how to perform such risk assessments. Twenty-two GPs (36.1\%) referred patients for cancer genetic counselling. Of this group, 54.5\% (12/22) referred patients to the Clinical and Counselling Section in the Division of Human Genetics, NHLS/Wits, while $45.5 \%$ (10/22) referred patients to other facilities that do not have trained genetic counsellors and medical geneticists.

\section{Knowledge about genes and genetic testing for cancer} When asked about available testing, more participants knew about the tests for breast cancer than about those available for colon cancer (Table 3). About a third (18/61) of GPs correctly responded that $<10 \%$ of females with breast and ovarian cancer are at risk of carrying a known BRCA1/2 gene mutation. Only 27/61 (44.3\%) knew that a breast cancer mutation can be inherited from the paternal side. Further, only $4.9 \%$ (3/61) correctly responded to a question about the penetrance of HNPCC mutations (i.e. that penetrance is about $\geq 50 \%$ ).

Most of the GPs $(57 / 61,83.4 \%)$ thought that patients should have genetic counselling before having genetic testing, while many $(39 / 61$, $63.9 \%$ ) expected that the numbers of patients undergoing cancer genetic testing would increase in the future and that they would be involved in the testing process.

All the GPs $(61 / 61,100 \%)$ agreed that a genetic counsellor is the most qualified professional to provide genetic counselling to patients, followed by a medical geneticist $(52 / 61,85.2 \%)$ and an oncologist (42/61, 68.9\%). Most (40/61, 65.6\%) believed that they themselves were not sufficiently qualified and equipped to provide genetic counselling for hereditary cancers.

\section{Attitudes regarding continuing medical education in cancer genetics}

Most GPs (57/61, 93.4\%) who participated in this study believed that genetic counselling should be offered prior to testing. Furthermore they reported being interested in learning more about hereditary cancers and becoming more involved in referring at-risk patients appropriately $(53 / 61,86.9 \%)$. The majority $(60 / 61$, $98.4 \%$ ) of GPs believed that there was a need for guidelines on cancer genetics. They felt that continuing medical education sessions $(53 / 61,86.9 \%)$, discussions with their colleagues $(50 / 61$, $82.0 \%)$, guidelines from government, societies and agencies (50/61, $82.0 \%)$ and data published in scientific journals $(54 / 61,88.5 \%)$ were important resources from which they could learn more about cancer genetics.

\section{Discussion}

This is the first published study exploring the practice, knowledge and attitudes of GPs in SA regarding their knowledge of hereditary cancer and genetic counselling and testing. Although this was a small study, the knowledge and attitudes of the cohort were similar to those reported from similar surveys of GPs and specialists in other parts of the world..$^{[4-7]} \mathrm{A}$ study by Nippert et al.$^{[10]}$ showed that

\begin{tabular}{|c|c|c|}
\hline $\begin{array}{l}\text { Inherited cancer } \\
\text { syndrome }\end{array}$ & Associated genes & $\begin{array}{l}\text { Testing available, } \\
n(\%)\end{array}$ \\
\hline НBOC & $B R C A 1$ and $B R C A 2$ & $28(45.9)$ \\
\hline Lynch syndrome/HNPCC & $h M S H 2$ and $h M L H 1$ & $8(13.1)$ \\
\hline FAP & $A P C$ & $9(14.8)$ \\
\hline
\end{tabular}

confidence on the part of participating physicians in their ability to carry out basic medical genetics tasks was low.

The key to identifying individuals at risk for an inherited cancer is to assess their family history carefully, ${ }^{[1]}$ so that responses can be provided to the items presented in Table 1 . The results of the present study showed that $26.2 \%$ (16/61) of the GPs did not collect a sufficiently comprehensive family history, which should include second-degree family members and the age of cancer onset in affected individuals. Partial family history information would limit a GP's ability to assess the risks for an inherited cancer susceptibility. These findings support those reported in two studies in the USA on taking, interpreting and assessing cancer family history by family physicians. ${ }^{[11,12]}$ These studies further found that family physicians lack confidence and available time to assess and communicate hereditary cancer risks. In the current study, $75.4 \%$ of GPs were not certain of how to assess their patients' risks for a hereditary cancer and few (36.1\%) referred patients to appropriate cancer genetic services. This finding suggests that GPs are not equipped with the correct knowledge and tools to assess their patients' risks for hereditary cancers, and many are unaware of the available cancer genetic services. A suggested solution could be to create appropriate risk assessment and referral guidelines similar to those of the National Institute for Health and Care Excellence (NICE) in the $\mathrm{UK}^{[13]}$ for use in the SA situation. These guidelines should enable healthcare professionals to identify patients at risk and refer them appropriately for more advanced risk assessment, cancer genetic counselling and possibly genetic testing.

An assessment of the GPs' knowledge about key cancer genetic concepts and genetic testing for HBOC, HNPCC and FAP showed an overall better understanding of HBOC. A possible explanation is that $\mathrm{HBOC}$ is more common and has probably had more media coverage than other cancer syndromes. ${ }^{[14]}$ About a third of the GPs understood that $5-10 \%$ of breast and/or ovarian cancers are inherited, and $44.3 \%$ knew that the BRCA genes causing HBOC can be inherited from the paternal line. These findings were very similar to those reported by Wideroff et al., ${ }^{[4]}$ who investigated HBOC, HNPCC and FAP genetic knowledge in a national sample of US physicians. The penetrance of HNPCC genes is $\geq 50 \%$ (i.e. only about half the individuals who carry the gene will show signs and symptoms). In the present study only 5\% of GPs understood this fact correctly, compared with $13 \%$ reported by Wideroff et al. ${ }^{[4]}$ Also, at the time we did our study, diagnostic testing for HBOC was available, whereas genetic testing for HNPCC and FAP is mostly only available on a research basis. Diagnostic testing, when necessary, was at the time of the study referred to reputable laboratories overseas. However, even in the absence of genetic testing individuals can benefit from genetic counselling, so that they understand their risks and make informed choices about management and future options.

It is strongly recommended that patients have genetic counselling prior to any genetic testing. A genetic counsellor can assess risks, empower the counselee with information regarding the testing procedures, discuss the advantages and limitations of the tests, and promote informed choices, as well as provide empathic emotional support throughout the whole process. ${ }^{[15]} \mathrm{A}$ very positive finding was that the GPs understood this recommendation, and 93.4\% (57/61) agreed that patients should have genetic counselling prior to genetic testing.

Fry et al. ${ }^{[6]}$ found that many GPs in Edinburgh, UK, did not feel equipped to counsel patients about cancer risks. These findings support those reported in the current study, where $65.6 \%$ of GPs reported that they did not feel qualified or equipped to provide cancer genetic counselling for hereditary cancers. Another study 
in the USA investigated possible reasons why GPs did not want to counsel patients about inherited cancers, and attributed their reluctance to time constraints. ${ }^{[4]}$ However, a study by Watson et al..$^{[7]}$ has shown that GPs are prepared to be gatekeepers and participate in family history taking, deciding which patients to refer for genetic counselling and testing, and managing at-risk patients with a predisposition to cancer. In the current study, GPs showed interest in being more involved in providing cancer genetic services and $86.9 \%(53 / 61)$ wanted to learn more about specific areas of inherited cancer and the available genetic services. There is therefore a need for continuing medical education, the development of specific guidelines in the field, and articles in scientific journals. Such an awareness programme, which includes the distribution of information booklets, cancer genetics pamphlets, educational lectures and workshops, has already been initiated.

\section{Conclusions}

The findings from this study showed GPs have limited knowledge about basic concepts of hereditary cancers and available local genetic counselling and testing services. As a result, at-risk patients and their families may not be identified or referred for specialist care and management. Fortunately, however, GPs are interested in learning more about hereditary cancers and in becoming more involved in referring at-risk patients appropriately.

It has been suggested that public awareness about the rapid advances in cancer genetics and inherited cancer syndromes would increase the demand for cancer genetic services and testing. ${ }^{[16]}$ Within the past 10 years the numbers of breast, ovarian and colorectal cancer cases seen in the Division of Human Genetics in Johannesburg has increased rapidly. This demand is expected to increase even more in the future, as has occurred in other human genetics departments such as the Queensland Clinical Genetics Service in Australia. ${ }^{[17]}$ It is therefore necessary to meet the educational needs of GPs by putting together and circulating informational documents and pamphlets about the common hereditary cancers, as well as referral guidelines. The NICE guidelines ${ }^{[13]}$ were developed to address primary, secondary and tertiary healthcare professionals and to guide them in classifying and caring for women at risk of breast cancer. Further research involving SA's unique population and the local healthcare system could enable the development of a similar document, which should be a quick and easy guide for all healthcare professionals. HBOC in black African patients is currently poorly understood, but local patient samples have been studied in an MSc dissertation and guidelines for identifying at-risk patients have been recommended. ${ }^{[18]}$

As an outcome of the present study, the professional staff of the Division of Human Genetics, NHLS/Wits are attempting to meet some of GPs' educational needs. Pamphlets have been distributed, advertising services provided and workshops and talks on cancer genetics held. At the same time, medical students are receiving training, in this field, which should be of benefit in future to families with a hereditary cancer syndrome.

Acknowledgements. We thank the GPs who participated in this study, the staff of the Department of Family Medicine of the University of the Witwatersrand, Prof. Bruce Sparks for assisting with the sample selection, Dr L Wideroff from the National Cancer Institute, Bethesda, USA, for permission to adapt and use her questionnaire, the Division of Human Genetics, NHLS/Wits for funding for the project, and Prof. Marion McAllister, University of Cardiff, Wales, for final editorial advice.

\section{References}

1. Lalloo F, Kerr B, Friedman JM, Evans DGR. Risk Assessment and Management in Cancer Genetics. New York: Oxford University Press, 2006:3-12.

2. Familial Cancer Database Online. Familial cancer syndromes. 2011. http://www.familialcancerdatabase, $\mathrm{nl} /$ (accessed 26 July 2015)

3. McKelvey KD Jr, Evans JP. Cancer genetics in primary care. J Nutr 2003;133(11 Suppl 1):3767S-3772S.

4. Wideroff L, Vadaparampil ST, Greene MH, Taplin S, Olson L, Freedman AN. Hereditary breast/ ovarian and colorectal cancer genetics knowledge in a national sample of US physicians. J Med Genet 2005;42(10):749-755. [http://dx.doi.org/10.1136/jmg.2004.030296]

5. Escher M, Sappino AP. Primary physicians' knowledge and attitudes towards genetic testing for breast5. Escher M, Sappino AP. Primary physicians' knowledge and attitude
ovarian cancer predisposition. Ann Oncol 2000;11(9):1131-1135.

6. Frarian cancer predisposition. Ann Oncol 2000;11(9):1131-1135.
6. Campbell H, Gudmunsdottir H, et al. GPs' views on their role in cancer genetics services and 6. Fry A, Campbell H, Gudmunsdottir H, et al. GPs' views on their role in cancer genetics serv
current practice. Fam Pract 1999;16(5):468-474. [http://dx.doi.org/10.1093/fampra/16.5.468]

7. Watson EK, Shickle D, Qureshi N, Emery J, Austoker J. The 'new genetics' and primary care: GPs' views on their role and their educational needs. Fam Pract 1999;16(4):420-425. [http://dx.doi.org/10.1093/ fampra/16.4.420]

8. Larson PD. A note on mail surveys and response rates in logistics research. Journal of Business Logistics 2005;26(2):211-222. [http://dx.doi.org/10.1002/j.2158-1592.2005.tb00212.x]

9. Neuman WL. Social Research Methods: Qualitative and Quantitative Approaches. 7th ed. Boston: Allyn \& Bacon, 2009:640.

10. Nippert I, Harris HJ, Julian-Reynier C, et al. Confidence of primary care physicians in their ability to carry out basic medical genetic tasks - a European survey in five countries - Part 1. J Community Genet 2011;2(1):1-11. [http://dx.doi.org/10.1007/s 12687-010-0030-0]

11. Tyler CV, Snyder CW. Cancer risk assessment: Examining the family physician's role. J Am Board Fam Med 2006;19(5):468-477. [http://dx.doi.org/10.3122/jabfm.19.5.468]

12. Wood ME, Stockdale A, Flynn BS. Interviews with primary care physicians regarding taking and Wood ME, Stockdale A, Flynn BS. Interviews with primary care physicians regarding taking and
interpreting the cancer family history. Fam Pract 2008;25(5):334-340. [http://dx.doi.org/10.1093/ fampra/cmn053]

13. National Institute for Health and Care Excellence (NICE). 2013. http://www.nice.org.uk/ (accessed 27 September 2013).

14. Gerlach KK, Marino C, Hoffman-Goetz L. Cancer coverage in women's magazines: What information are women receiving? J Cancer Educ 1997;12(4):240-244. PMID: 9440017. [http://dx.doi. org/10.1080/08858199709528496]

15. Resta R, Biesecker BB, Bennett RL, et al. New Definition of Genetic Counseling: National Society of Genetic Counsellors' Task Force Report. J Genet Couns 2006;15(2):77-83. [http://dx.doi.org/10.1007/ s10897-005-9014-3]

16. Bathurst L, Huang QR. A qualitative study of GPs' views on modern genetics. Aust Fam Physician 2006;35(6):462-464.

17. Kromberg JGR, Parkes J, Taylor S. Genetic counselling as a developing healthcare profession: A case study in the Queensland context. Aust J Prim Health 2005;12(1):33-39. [http://dx.doi.org/10.1071/ PY06006]

18. Wainstein T. Family history and risk assessment in black South African women with breast cancer. MSc (Med) dissertation. Johannesburg: University of the Witwatersrand, 2011:70. http://wiredspace. wits.ac.za/bitstream/handle/10539/11052/0611283G_TASHA\%20WAINSTEIN_RESEARCH\%20 REPORT_CORRECTED_FINAL_11\%20.pdf? sequence=1 (accessed 1 October 2015).

Accepted 5 October 2015. 